\title{
Controlled-release formulation of perindopril erbumine loaded PEG-coated magnetite nanoparticles for biomedical applications
}

\author{
Dena Dorniani - Aminu Umar Kura • \\ Mohd Zobir Bin Hussein · Sharida Fakurazi • \\ Abdul Halim Shaari · Zalinah Ahmad
}

Received: 2 May 2014/Accepted: 18 August 2014/Published online: 9 September 2014

(C) The Author(s) 2014. This article is published with open access at Springerlink.com

\begin{abstract}
Iron oxide nanoparticles (FNPs) were synthesized due to low toxicity and their ability to immobilize biological materials on their surfaces by the coprecipitation of iron salts in ammonia hydroxide followed by coating it with polyethylene glycol (PEG) to minimize the aggregation of iron oxide nanoparticles and enhance the effect of nanoparticles for biological applications. Then, the FNPsPEG was loaded with perindopril erbumine (PE), an antihypertensive compound to form a new nanocomposite (FPEGPE). Transmission electron microscopy results showed that there are no significant differences between the sizes of FNPs and FPEGPE nanocomposite. The existence of PEG-PE was supported by the FTIR and TGA analyses. The PE loading $(10.3 \%)$ and the release profiles from FPEGPE nanocomposite were estimated using ultraviolet-visible spectroscopy which showed that up to 60.8 and $83.1 \%$ of the adsorbed drug was released in 4223 and $1231 \mathrm{~min}$ at $\mathrm{pH} 7.4$ and 4.8, respectively. However, the release of PE was completed very fast from a physical
\end{abstract}

\footnotetext{
D. Dorniani · M. Z. B. Hussein $(\bowtie)$

Materials Synthesis and Characterization Laboratory (MSCL), Institute of Advanced Technology (ITMA), Universiti Putra

Malaysia, 43400 Serdang, Selangor, Malaysia

e-mail: mzobir@upm.edu.my

D. Dorniani

e-mail: dena_dorniani@yahoo.com

A. U. Kura · S. Fakurazi · Z. Ahmad

Vaccines and Immunotherapeutics Laboratory (IBS), Universiti

Putra Malaysia, 43400 Serdang, Selangor, Malaysia

e-mail: aminuukura@yahoo.com

S. Fakurazi

e-mail: sharida@upm.edu.my

Z. Ahmad

e-mail: zalinah@upm.edu.my
}

mixture (FNPs-PEG-PE) after 5 and $7 \mathrm{~min}$ at $\mathrm{pH} 4.8$ and 7.4 , respectively, which reveals that the release of $\mathrm{PE}$ from the physical mixture is not in the sustained-release manner. Cytotoxicity study showed that free PE presented slightly higher toxicity than the FNPs and FPEGPE nanocomposite. Therefore, the decrease toxicity against mouse normal fibroblast (3T3) cell lines prospective of this nanocomposite together with controlled-release behavior provided evidence of the possible beneficial biological activities of this new nanocomposite for nanopharmaceutical applications for both oral and non-oral routes.

\section{Introduction}

Recently, different types of nanoparticles-based therapeutic and diagnostic agents have been extensively studied to prolong the half-life of drug systemic circulation by reducing immunogenicity, sustained release of drugs in an environmentally responsive manner, lower frequency of

\footnotetext{
A. H. Shaari

Department of Physics, Faculty of Science, Universiti Putra Malaysia, 43400 Serdang, Selangor, Malaysia

e-mail: ahalim@upm.edu.my
}

\author{
A. H. Shaari \\ Department of Physics, Faculty of Science, Universiti Putra \\ Malaysia, Serdang, Selangor, Malaysia \\ Z. Ahmad \\ Chemical Pathology Unit, Department of Pathology, Faculty of \\ Medicine and Health Sciences, Universiti Putra Malaysia, \\ 43400 Serdang, Selangor, Malaysia
}


administration in order to minimize systemic side effects of drugs for treatment of diabetes [1, 2], asthma [3-5], allergy [6], infections [7, 8], cardiovascular diseases [9], neurological diseases [10], cancers [11, 12], pain, and so on. Therefore, a few pioneering therapeutic nanoparticles have been introduced into the pharmaceutical market.

Polymeric nanoparticles [13] have been used in nanomedicine to provide more effective and/or more convenient routes of administration, high encapsulation efficiency [14], lower therapeutic toxicity, extend the product life cycle, and ultimately reduce health-care costs.

Beside polymeric nanoparticles, the most common nanoparticles attracted more attention nowadays are polysaccharide-based nanoparticles and metallic nanoparticles (typically iron oxide nanoparticles) [15] which could improve the therapeutic index of drugs by reducing the drug toxicity or enhancing drug efficacy. Previous studies showed that polymeric nanoparticles could be used to prevent the hemoglobin oxidation after loading into VAM41-polyethylene glycol (PEG) [16]. In the early 1990s, PEG, a non-toxic and non-immunogenic polymer was introduced into clinical uses in order to enhance the pharmacokinetics of various nanoparticle formulations and prolongs drug circulation half-life [17, 18].

Controlled release of drug suggests plenty advantages over free drugs such as improved efficacy, reduced side effects, and improved patient compliance [18]. Previous reports showed that a variety of active compounds such as kojic acid [19], doxorubicin [20, 21], 5-aminosalicylic acid [22], 6-mercaptopurine [23], 10-hydroxycamptothecin [24], gallic acid [25, 26], folic acid [27], arginine [28], and anthranilic acid [29] can be loaded onto the surface of magnetic nanoparticles.

Heart disease is the first leading cause of death for both men and women globally and the number of people who die due to high blood pressure (BP) (hypertension) will increase to reach 23.3 million by 2030 [30]. Therefore, to find a new nanocomposite for the treatment of hypertension, iron oxide nanoparticles can be selected due to low toxicity, low cost of production, ability to immobilize biological materials on their surfaces, potential for direct biodegradable, and suitable for surface modifications. To minimize the aggregation of iron oxide nanoparticles (FNPs), which causes due to dipole-dipole attractions between particles [31, 32], PEG was coated on the surface of FNPs to create FNPs-PEG. Then, perindopril erbumine (PE), a long-acting angiotensinconverting enzyme inhibitor, which prevents various medical conditions indicating reduced systolic and diastolic BP in patients with mild-to-moderate hypertension, congestive heart failure and diabetic nephropathy $[33,34]$ was loaded on the surface of FNPs-PEG and formed a new FPEGPE nanocomposite. The resulting nanocomposites (FPEGPE) was characterized for the structural and sustained release properties and evaluate the cytotoxic effects against normal fibroblast (3T3) cell lines as compared to free active drug and uncoated FNPs in order to improve the treatment of hypertension. In addition, the effect of PEG coating will be also evaluated.

\section{Materials and methods}

\section{Materials}

Ferrous chloride tetrahydrate $\left(\mathrm{FeCl}_{2} \cdot 4 \mathrm{H}_{2} \mathrm{O} \geq 99 \%\right)$ and ferric chloride hexahydrate $\left(\mathrm{FeCl}_{3} \cdot 6 \mathrm{H}_{2} \mathrm{O}, 99 \%\right)$ were obtained from Merck KGaA, Darmstadt, Germany. In order to coat FNPs with polymer, PEG with average M.W. 6000 was used, as a raw material from Acros Organics. PE $\left(\mathrm{C}_{23} \mathrm{H}_{43} \mathrm{~N}_{3} \mathrm{O}_{5}\right.$, with molecular weight $\left.441.6 \mathrm{~g} \mathrm{~mol}^{-1}\right)$ was purchased from CCM Duopharma (Klang, Malaysia) at $99.79 \%$ purity. Distilled deionized water $\left(18.2 \mathrm{M} \Omega \mathrm{cm}^{-1}\right)$ was used throughout the experiments. In addition, all reagents used in this study were of analytical grade and were used without further purification.

\section{Preparation of magnetite nanoparticles and FPEGPE} nanocomposite

The magnetite nanoparticles were synthesized by coprecipitation method as previously reported by Lee et al. [35]. The magnetite nanoparticles were prepared by mixing of $2.43 \mathrm{~g}$ ferrous chloride tetrahydrate, $0.99 \mathrm{~g}$ ferric chloride hexahydrate, and $80 \mathrm{~mL}$ of deionized water in the presence of $6 \mathrm{~mL}$ of ammonia hydroxide (25 mass \%). The $\mathrm{pH}$ of the solution was keep at 10 . The solution was ultrasonicated for $1 \mathrm{~h}$ at room temperature. To remove all impurities, the precipitates were centrifuged and washed with deionized water for three times. For surface modification of FNPs, the collected magnetite was mixed with $2 \%$ PEG. After $24 \mathrm{~h}$ stirring, the black precipitates mixture of magnetite-PEG was collected by a permanent magnet, washed for three times in order to remove the unbound PEG during the coating process. The $2 \%$ of drug solution, PE which was dissolved in deionized water was added to the magnetite-PEG, and the mixture was magnetically stirred at room temperature for $24 \mathrm{~h}$ to facilitate the uptake of PE. Finally, the FPEGPE products (PE-loaded PEG-coated magnetite nanoparticle) were washed for three times and dried in an oven.

Cell viability study

\section{Cell culture}

Mouse normal fibroblast (3T3) cell line was obtained from American Type Culture Collection (Manassas, VA, USA). They were maintained in DMEM medium (Dulbecco's 
Modified Eagle Medium, Gibco) supplemented with $10 \%$ fetal bovine serum and $1 \%$ antibiotics (100 units $\mathrm{mL}^{-1}$ penicillin $100 \mathrm{mg} \mathrm{mL}^{-1}$ streptomycin). Cell's media were changed after every 2 days, and they were grown in a humidified incubator at $37{ }^{\circ} \mathrm{C}\left(95 \%\right.$ room air, $\left.5 \% \mathrm{CO}_{2}\right)$ and used for seeding and treatment after reaching $90 \%$ confluence.

The 3 T3 cells were seeded at $1 \times 10^{5}$ cells $\mathrm{mL}^{-1}$ into 96-well plates and left overnight in a $\mathrm{CO}_{2}$ incubator to become attached. Cytotoxic activity of the coated FNPs with PEG-PE, pure PE, and the uncoated FNPs was done after $72 \mathrm{~h}$ exposure. A stock solution of $10 \mathrm{mg} \mathrm{mL}^{-1}$ from nanoparticles, the FPEGPE nanocomposite, and pure PE was prepared in media and subsequently diluted to obtain the desired concentration of $0.47-50.0 \mu \mathrm{g} \mathrm{mL}^{-1}$. Wells containing cells and media only were used as control.

\section{Cytotoxicity study}

The cytotoxic effect of the FNPs, FPEGPE nanocomposite, and pure drug (PE) on the cells was measured by the conventional MTT reduction assay as described previously [36]. MTT solution (5 mg mL $\mathrm{mL}^{-1}$ in phosphate buffered salinePBS) was added to the treated and control wells at $20 \mu \mathrm{L}$ final volume and then left in an incubator at $37{ }^{\circ} \mathrm{C}$. Media were discarded about $2 \mathrm{~h}$ post MTT solution addition, and the reaction was stopped by gentle replacement with dimethyl sulfoxide (DMSO) $100 \mu \mathrm{L}$ per well. This is to dissolve the blue crystals formed due to the reduction of tetrazolium by living cells. The amount of MTT formazan produced was determined by measuring the absorbance at 570 and $630 \mathrm{~nm}$ (background) using a microplate enzyme-linked immunosorbent assay reader (ELx800, BioTek Instruments, Winooski, VT, USA). All experiments were carried out in triplicate, and the results are presented as the mean \pm standard deviation. Cell viability was expressed as a percentage of the value in untreated control cells and calculated as

Cell viability $(\%)=\frac{[\text { Average }] \text { test }}{[\text { Average }] \text { control }} \times 100$.

Loading and release amounts of PE from FPEGPE nanocomposite

The loading percentage of PE in the FPEGPE nanocomposite was measured spectrophotometrically. A measure of $11 \mathrm{mg}$ of FPEGPE nanocomposite was dissolved into the mixture of 1:3 mL $\mathrm{HCl} \mathrm{HNO}_{3}^{-1}$ and marked it up to $25 \mathrm{~mL}$ by deionized water and stirred for around $1 \mathrm{~h}$. Then, the amount of the PE in the sample was measured using a $\mathrm{UV}-\mathrm{V}$ is spectroscopy.

To study the release profiles of PE from FPEGPE nanocomposite, a PBS solution at two pH levels (7.4 and 4.8) was used at room temperature [37, 38]. The cumulative released amount of PE into the solution was measured at preset time intervals at $\lambda_{\max }=215 \mathrm{~nm}$ by the $\mathrm{UV}-\mathrm{V}$ is spectrum. The rate of the release can be changed due to existing different anions such as $\mathrm{Cl}^{-}, \mathrm{HPO}_{4}{ }^{2-}$, and $\mathrm{H}_{2} \mathrm{PO}_{4}{ }^{-}$in the PBS.

\section{Instrumentation}

In order to determine the crystal structure of the magnetite and FPEGPE nanocomposite, powder X-ray diffraction (XRD) patterns were obtained in a range of $5^{\circ}-70^{\circ}$ on an XRD-6000 diffractometer (Shimadzu, Tokyo, Japan) using $\mathrm{CuK}_{\alpha}$ radiation $(\lambda=1.5406 \AA)$ at $40 \mathrm{kV}$ and $30 \mathrm{~mA}$. Fourier transform infrared (FTIR) spectra of the materials were recorded over the range of $400-4000 \mathrm{~cm}^{-1}$ on a Thermo Nicolet (AEM, Madison WI, USA) with $4 \mathrm{~cm}^{-1}$ resolution, using the potassium bromide disk method. Thermogravimetric and differential thermogravimetric analyses (TGA-DTG) were carried out using a MettlerToledo instrument (Greifensee, Switzerland) in $150 \mu \mathrm{L}$ alumina crucibles in the range of $20-1000{ }^{\circ} \mathrm{C}$ at a heating rate of $10{ }^{\circ} \mathrm{C} \mathrm{min}^{-1}$. Magnetic properties were obtained by a Lakeshore 7404 vibrating sample magnetometer (VSM; Westerville, OH, USA). Morphology and particle size of the samples were determined by a transmission electron microscopy (TEM) (Hitachi, H-7100 at an accelerating voltage of $100 \mathrm{kV}$ ). The UV-Vis spectrophotometer (Shimadzu 1650 series, Tokyo, Japan) was used to determine the optical and controlled-release properties of PE from the FPEGPE nanocomposite.

\section{Results and discussion}

\section{Powder XRD}

The XRD patterns of the prepared magnetite nanoparticles as well as FPEGPE nanocomposite are shown in Fig. 1. The inset shows the XRD patterns of pure PE and the PEG. Two main diffraction peaks appeared at $2 \theta=10.5^{\circ}$ and $20.6^{\circ}$ can be assigned to the pure PEG (Fig. 1d) [39]. The diffraction pattern of pure PE (Fig. 1c) shows many intense sharp peaks in the fingerprint region, which was also previously reported [40]. Figure 1a shows six characteristic peaks of FNPs which are marked by their indices (220), (311), (400), (422), (511), and (440). These peaks confirm the formation of cubic inverse spinal structure of magnetite $\mathrm{Fe}_{3} \mathrm{O}_{4}$ nanoparticles [41].

Due to the same characteristic peaks that can be observed in FPEGPE nanocomposite, it can be proved that the modification of FNPs after coating with PEG-PE did not result in any phase change of magnetite FNPs [19, 42]. Moreover, the absence of the characteristic diffraction 


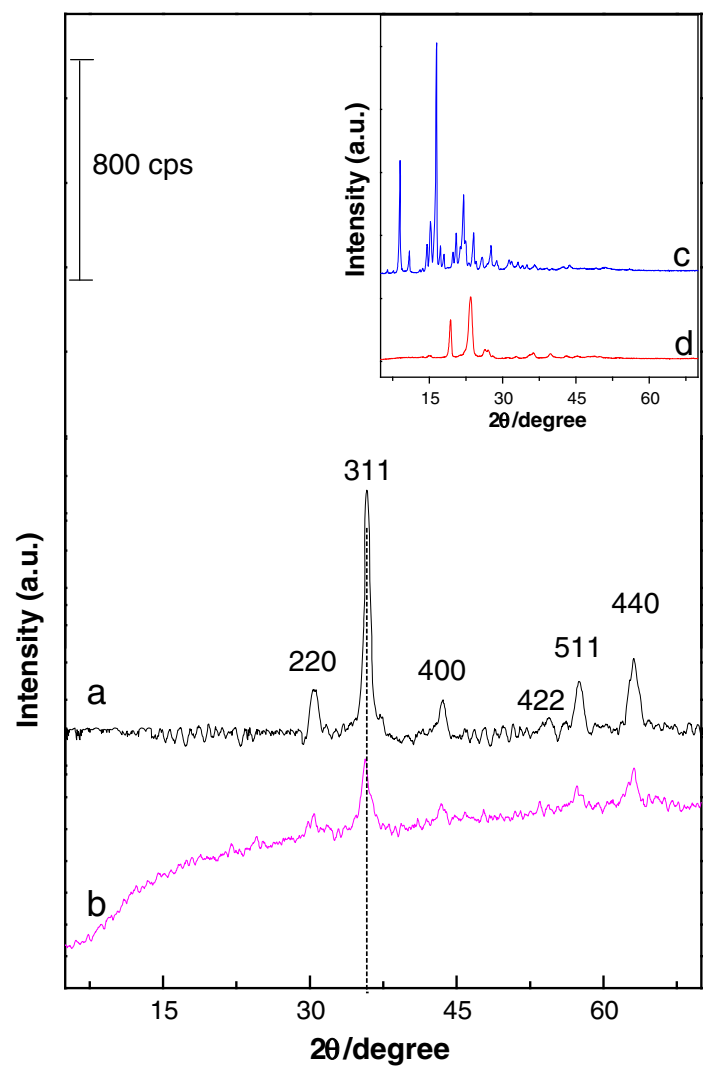

Fig. 1 XRD patterns of FNPs $(a)$, and FPEGPE nanocomposite $(b)$. The inset shows the XRD patterns of pure PE $(c)$ and pure PEG $(d)$

peaks at (210), (213), and (300) indicates that the maghemite or the co-existence of maghemite $\left(\gamma-\mathrm{Fe}_{2} \mathrm{O}_{3}\right)$ did not exist in both samples [43]. The mean grain size was measured using the Debye-Scherrer equation $(D=K \lambda /$ $\beta \cos \theta)$, where $D$ is the mean grain size, $K$ is the Scherrer constant (0.9), $\lambda$ is the XRD wavelength $(0.15418 \mathrm{~nm}), \beta$ is the peak width of half maximum intensity, and $\theta$ is the Bragg diffraction angle. Therefore, the average crystal size of the FNPs was estimated to be $3 \mathrm{~nm}$.

\section{Infrared spectroscopy}

Figure 2 provides the FTIR spectra of FNPs (a), pure PEG (b), free drug PE (c), and FPEGPE nanocomposite (d). The absorption peak at around $560 \mathrm{~cm}^{-1}$ in magnetic FNPs spectrum relates to the stretching of $\mathrm{Fe}-\mathrm{O}$ which was shifted to $577 \mathrm{~cm}^{-1}$ after coating with PEG-PE (Fig. 2d), confirming the presence of magnetite in FPEGPE nanocomposite. The characteristic band of pure PEG was appeared at $2889 \mathrm{~cm}^{-1}$ (Fig. 2b) and can be assigned to C-H stretching vibration which is shifted to $2872 \mathrm{~cm}^{-1}$ in FPEGPE nanocomposite. Another two bands at 1468 and $1343 \mathrm{~cm}^{-1}$ belong to the $\mathrm{C}-\mathrm{H}$ bending vibration. The $\mathrm{C}-\mathrm{H}$ bending vibration band at $1468 \mathrm{~cm}^{-1}$ is shifted to $1445 \mathrm{~cm}^{-1}$ after the coating process. In addition, two characteristic bands at

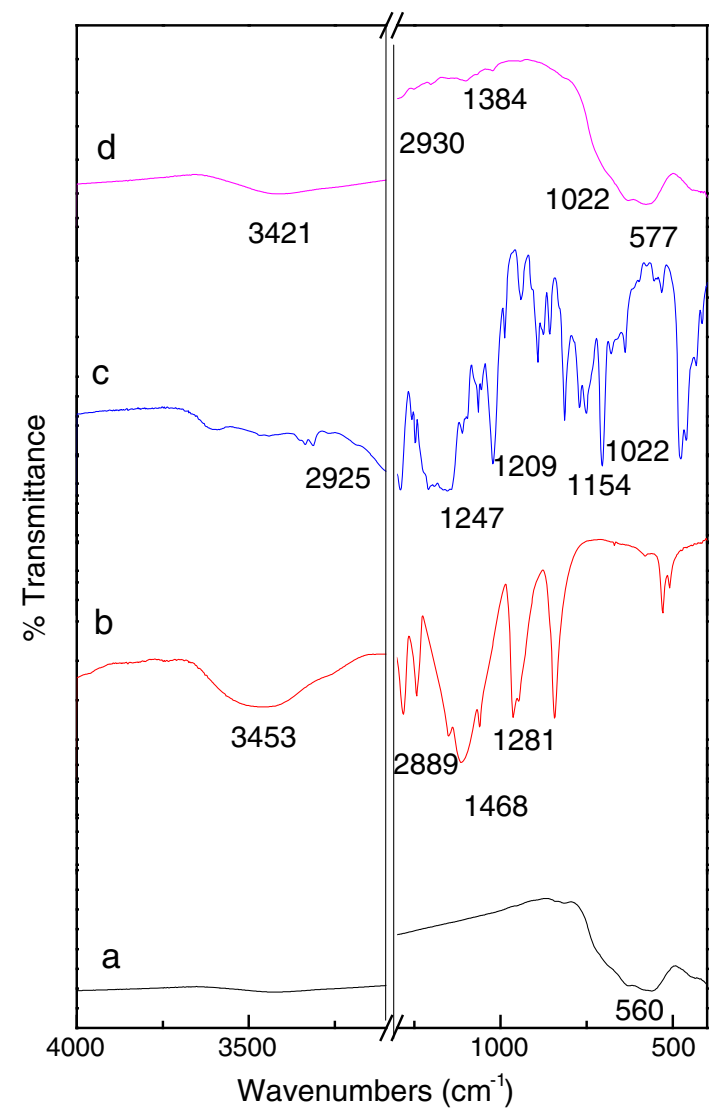

Fig. 2 FTIR spectra of FNPs $(a)$, pure PEG $(b)$, pure $\operatorname{PE}(c)$, and FPEGPE nanocomposite $(d)$

1281 and $1094 \mathrm{~cm}^{-1}$ can be assigned to the $\mathrm{O}-\mathrm{H}$ and $\mathrm{C}-\mathrm{O}-\mathrm{H}$ stretching vibration, respectively [44].

The FTIR spectra of PE (Fig. 2c) show many intense, sharp absorption bands due to different functional groups present in molecules such as primary amine, secondary amine, ester, carboxylic acid, and methyl groups. The peak at $1247 \mathrm{~cm}^{-1}$ is due to $\mathrm{C}_{3} \mathrm{C}-\mathrm{N}$ stretching [45], and it was shifted to $1251 \mathrm{~cm}^{-1}$ after coating process, demonstrating that PE was successfully loaded to FNPs-PEG. The band at $1022 \mathrm{~cm}^{-1}$ is due to $\mathrm{C}-\mathrm{N}$ stretching [46] and it is also present in FPEGPE nanocomposite. The band at $2925 \mathrm{~cm}^{-1}$ indicates that $\mathrm{CH}$ in NH-CH-propyl is shifted to $2930 \mathrm{~cm}^{-1}$ due to the coating procedure (Fig. 2d). The band appeared at $1154 \mathrm{~cm}^{-1}$ is due to the symmetric stretching of $\mathrm{C}-\mathrm{N}-\mathrm{C}$, which is also present in FPEGPE nanocomposite. This evidence strongly confirms the coating of PEG-PE on the surface of FNPs.

Thermogravimetric analysis

In order to verify the coating and loading formation of FNPs with PEG-PE, the thermal behavior of the FNPs, free drug (PE), and FPEGPE nanocomposite was measured via 

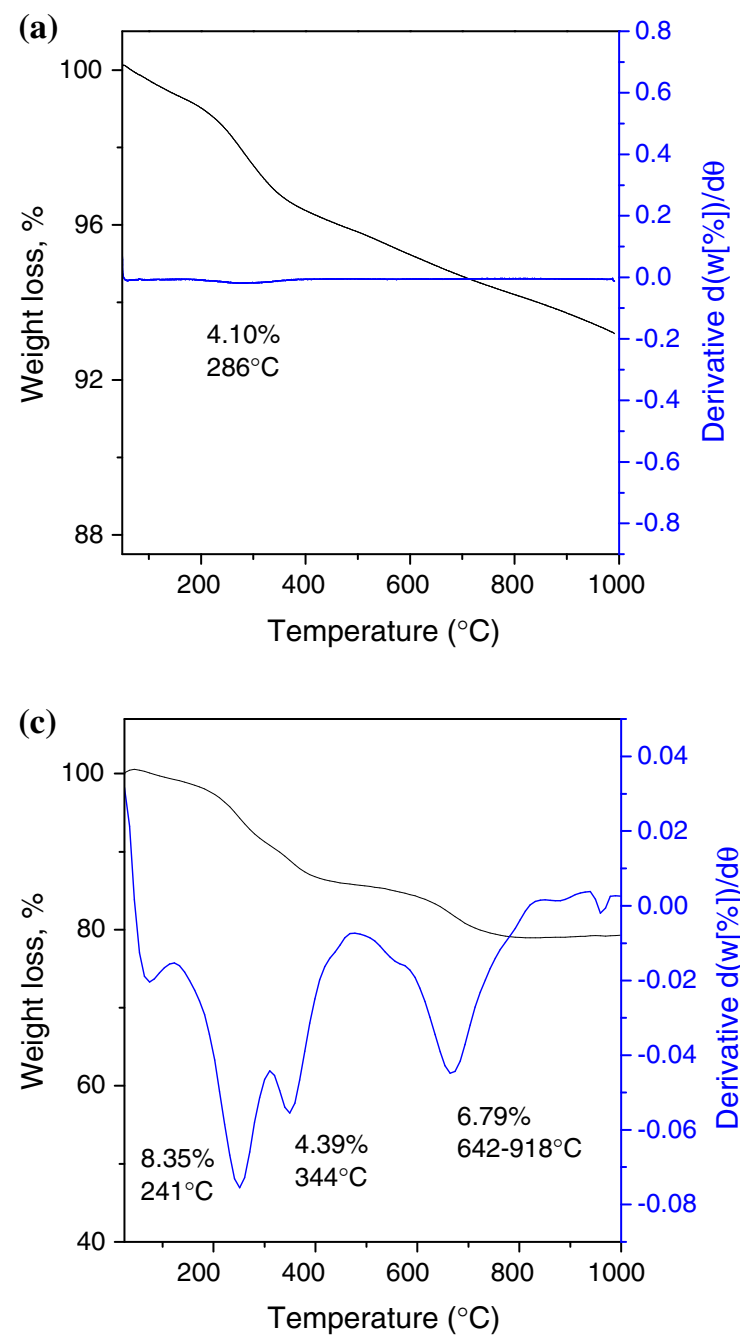

Fig. 3 TGA of a FNPs, b PE, and $\mathbf{c}$ FPEGPE nanocomposite

thermogravimetric and differential thermogravimetric analyses (Fig. 3). The FNPs show one stage weight loss which occurred at $286{ }^{\circ} \mathrm{C}$, which is corresponding to the loss of residual water with $4.1 \%$ weight loss (Fig. 3a) [32]. Thermogravimetric curve of free drug (PE) shows two main thermal stages. The first stage which is related to melting of PE was observed at $145{ }^{\circ} \mathrm{C}$ with about $18 \%$ weight loss (Fig. 3b). The second mass reduction at $260{ }^{\circ} \mathrm{C}$ with $78 \%$ weight loss is attributed to the decomposition and subtle combustion of PE [47].

For the FPEGPE nanocomposite, three major thermal events were observed (Fig. 3c). A slight mass reduction was observed up to $241{ }^{\circ} \mathrm{C}$ ( $8.4 \%$ weight loss) which is likely due to the adsorbed water and decomposition of PE. The second mass reduction at $344{ }^{\circ} \mathrm{C}$ might be due to the decomposition of PEG polymer with weight loss of $4.4 \%$. This was followed by the third stage in the region of $642{ }^{\circ} \mathrm{C}$ up to $918{ }^{\circ} \mathrm{C}$ with the mass reduction of $6.8 \%$.

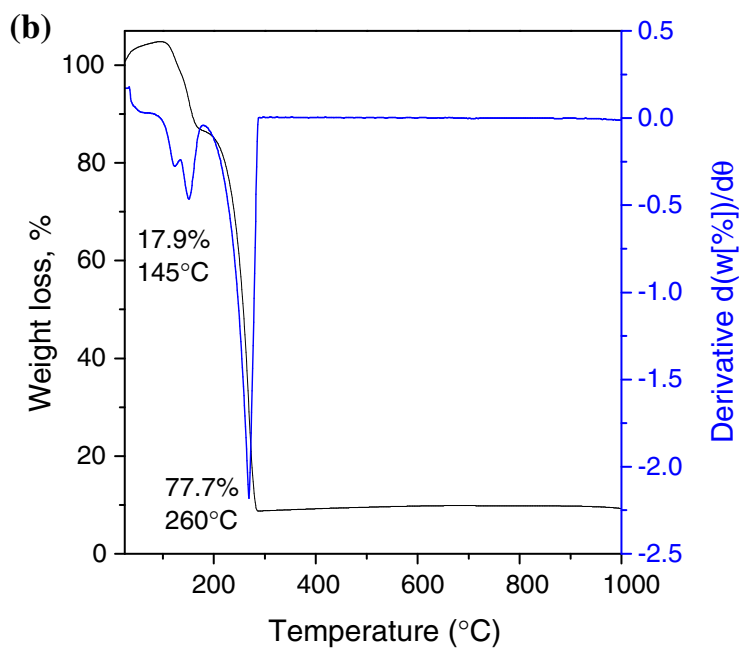

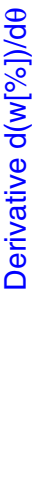

The temperature region after coating is clearly enhanced, due to the electrostatic attraction between the iron oxide surface and PEG-PE [40].

\section{Magnetic properties}

In drug delivery system, superparamagnetism is having an important role in magnetic targeting carriers [48]. Figure 4 shows the magnetic properties of FNPs (Fig. 4a) and FNPs coated with PEG-PE (FPEGPE), by a VSM (Fig. 4b). Due to the lack of hysteresis loop in the magnetization curves and the saturation magnetization of 54.6 and $38.8 \mathrm{emu} \mathrm{\textrm {g } ^ { - 1 }}$ for FNPs and FPEGPE nanocomposite, respectively, it can be confirmed that both samples have the superparamagnetic properties (i.e., no remanence effect) and were of soft magnets [24, 42, 48]. Method of synthesis and the particle size can be affected on the value of saturation magnetization; therefore, this value is usually lower than the 


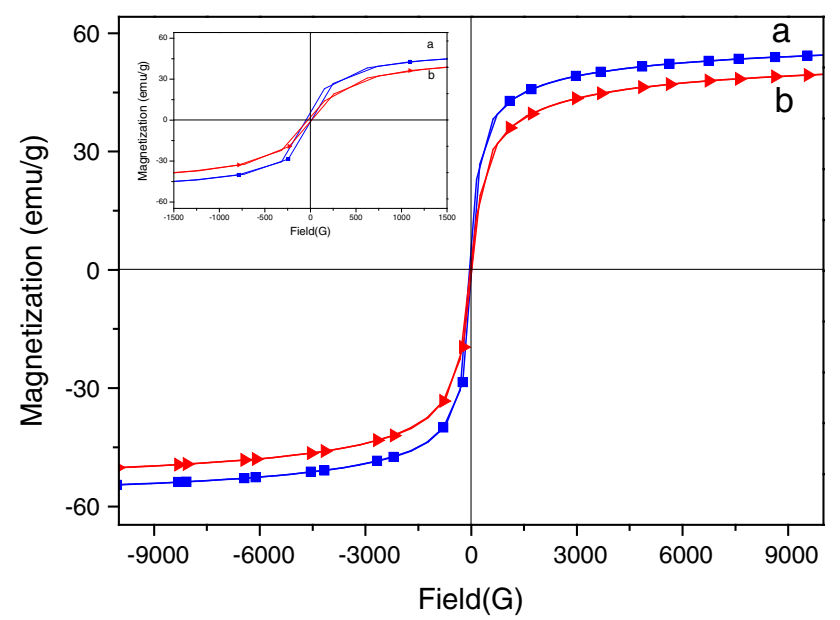

Fig. 4 Magnetization plots of (a) FNPs and (b) FPEGPE nanocomposite. The inset shows the magnetic behavior under low magnetic fields theoretical value expected [49]. Saturation magnetization (Ms) of FNPs decreased after coating procedure, which is attributed to the effect of small-particle surface and also the exchange of electrons between the surface of $\mathrm{Fe}$ atoms and the PEG polymer coating [50]. In addition, it can provide further supporting evidence of occurrence of the PEG on the surface of iron oxide magnetic nanoparticles.

Particle size and size distribution

Magnetic nanoparticles with smaller size $(<30 \mathrm{~nm})$ show superparamagnetic properties [28] therefore, TEM together with a UTHSCSA ImageTool software were performed to determine the size, shape, and particle size distribution of the bare FNPs (Fig. 5a, c) and FPEGPE nanocomposite (Fig. 5b, d). The particle size and size distribution of FNPs and FPEGPE nanocomposite were calculated by measuring
Fig. 5 TEM micrographs for a FNPs with $200 \mathrm{~nm}$ scale bar, b FPEGPE nanocomposite with $200 \mathrm{~nm}$ scale bar, $\mathbf{c}$ particle size distribution of FNPs, and d particle size distribution of FPEGPE nanocomposite
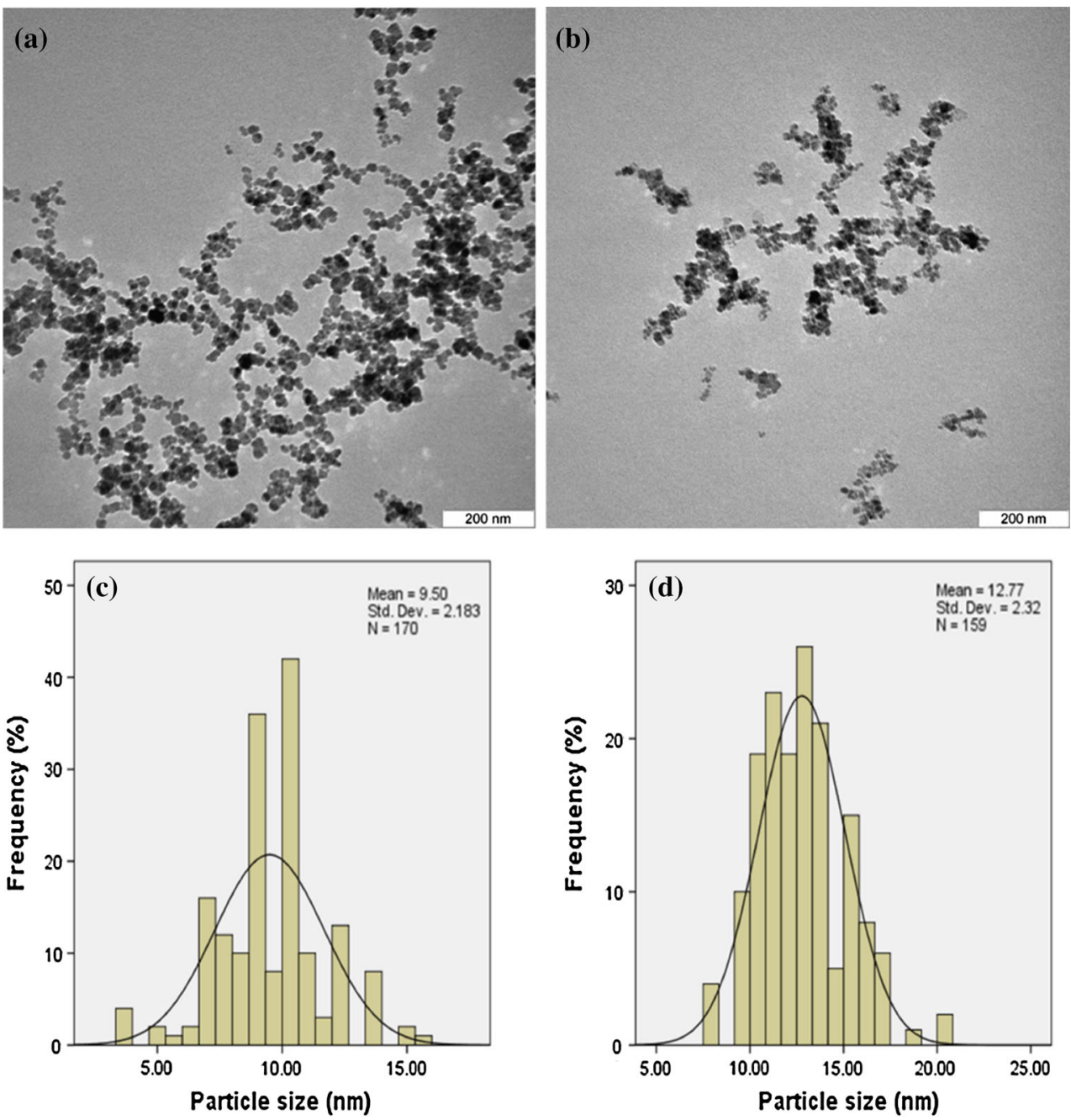


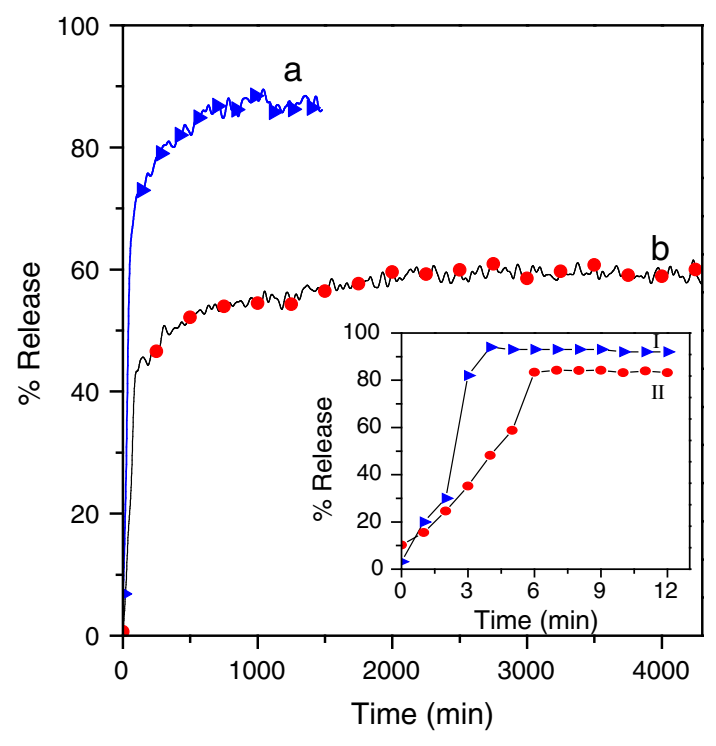

Fig. 6 Release profiles of PE from the FPEGPE nanocomposite into (a) phosphate buffered solution at $\mathrm{pH} 4.8$ and $(b) \mathrm{pH}$ 7.4. The inset shows the release profiles of PE from its physical mixture of FNPs-PEG-PE into phosphate buffered solution $(I)$ at $\mathrm{pH} 4.8$ and (II) at $\mathrm{pH} 7.4$

the diameters of around 150 nanoparticles chosen randomly through the TEM images. FNPs are well-dispersed and have uniform size and shape, although some agglomeration exist due to the magnetization effect [24] and/or the dehydration process. Figure 5 indicates that the pre-prepared FNPs and FPEGPE nanocomposite have spherical shape and were essentially monodisperse with the average size of $9 \pm 2$ and $13 \pm 2 \mathrm{~nm}$, for FNPs and FPEGPE nanocomposite, respectively. Due to increase of the particle size after coating, it is therefore proved that the PEG-PE was successfully coated on the surface of FNPs $[51,52]$.

\section{Release study of PE from FPEGPE nanocomposite}

Release profiles of PE from FPEGPE nanocomposite were investigated in PBSs at $\mathrm{pH} 7.4$ and 4.8 in order to simulate in vivo conditions similar to the body fluids and $\mathrm{pH}$ of stomach after digestion, respectively. By the UV spectrophotometer and a calibration curve equation, the percentage loading of PE into the FPEGPE nanocomposite was obtained to be around $10.3 \%$. Figure 6 provides the cumulative release quantities of PE from the FPEGPE nanocomposite were 60.8 and $83.1 \%$ at $\mathrm{pH} 7.4$ and 4.8 after 4223 and 1231 min, respectively. The inset in Fig. 6 shows as expected the release of PE was completed very fast from a physical mixture (FNPs-PEG-PE) after 5 and 7 min at $\mathrm{pH} 4.8$ and 7.4 , respectively, which reveals that the release of PE from the physical mixture is not in the sustained-release manner.
The release rates of $\mathrm{PE}$ from the nanocomposite at $\mathrm{pH}$ 7.4 (Fig. 6b) are much slower than that at pH 4.8 (Fig. 6a), and this behavior is attributed to the acidity of the media. At $\mathrm{pH} 7.4$, the fast release of PE with a value of $44.2 \%$ at the initial 120 min may be due to the release of PE anions adsorbed on the surface of the PEG polymer. However, it became much slower and more sustained after this initial time, which is attributed to the ion-exchange process between the PE anions and the anions present in the buffer solution. In our previous nanocomposite (FCPE) with chitosan was used as the coating polymer, the PE anion binding was found to be stronger compared to this nanocomposite (FPEGPE) due to the $\mathrm{NH}_{3}$ active group that is present in chitosan in FCPE nanocomposite compared to $\mathrm{O}-\mathrm{H}$ active group that is present in PEG in FPEGPE nanocomposite. Therefore, the drug (PE) can be released more slowly from the FCPE carriers, when chitosan was used as a coating polymer compared to FPEGPE nanocomposite in which PEG was used as the coating polymer [40].

The release of drug molecules from FPEGPE nanocomposite can be described by three different kinetic models such as pseudo-first-order kinetic, pseudo-secondorder kinetic, and parabolic diffusion model. Pseudo-firstorder kinetic equation, $\ln \left(q_{\mathrm{e}}-q_{\mathrm{t}}\right)=\ln \left(q_{\mathrm{e}}-k_{1} t\right)[53,54]$ which is represented in the linear form, shows the release of PE from FPEGPE nanocomposite, and the decomposition rate depends on the amount of the drug in the nanocomposite. Therefore, if this kinetic model is followed, the plot of $\ln \left(q_{\mathrm{e}}-q_{\mathrm{t}}\right)$ versus $t$ will be a linear from which the $k_{1}$ value can be obtained.

The pseudo-second-order kinetic model [54] that can be expressed in the linear form of $\frac{t}{q_{\mathrm{t}}}=\frac{1}{k_{2} q_{\mathrm{e}}{ }^{2}}+\frac{t}{q_{\mathrm{e}}}$. The plot of $\frac{t}{q_{\mathrm{t}}}$ versus $t$ will be a linear and allows to measure of $k_{2}$. And the parabolic diffusion model [55] which can be represented as, $1-\frac{\left(\frac{M_{\mathrm{t}}}{M_{0}}\right)}{t}=k t^{-0.5}+b$ equations. The $q_{\mathrm{e}}$ and $q_{\mathrm{t}}$ in the pseudo-first- and the pseudo-second-order kinetic models are the equilibrium release rate and the release rate at time $t$, respectively. In addition, $k$ in all the three models is a constant and corresponding to the release amount, and $M_{0}$ and $M_{\mathrm{t}}$ in parabolic equation are the drug content remained in FPEGPE nanocomposite at release time 0 and $t$, respectively. The correlation coefficient $\left(R^{2}\right)$ was used as criteria to select the best model for describing the release of drug from the nanocomposite.

With the use of these three kinetic models as mentioned earlier for the release kinetic data, it was found that the pseudo-second-order kinetic model was deemed more satisfactory for describing the release behavior of PE anions from FPEGPE nanocomposites compared to the other models used in this work (Fig. 7a, b, Table 1). 
(a)

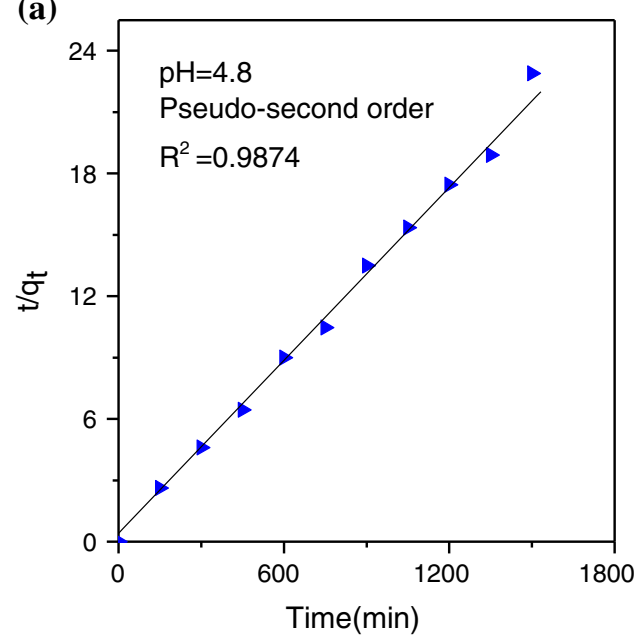

(b)

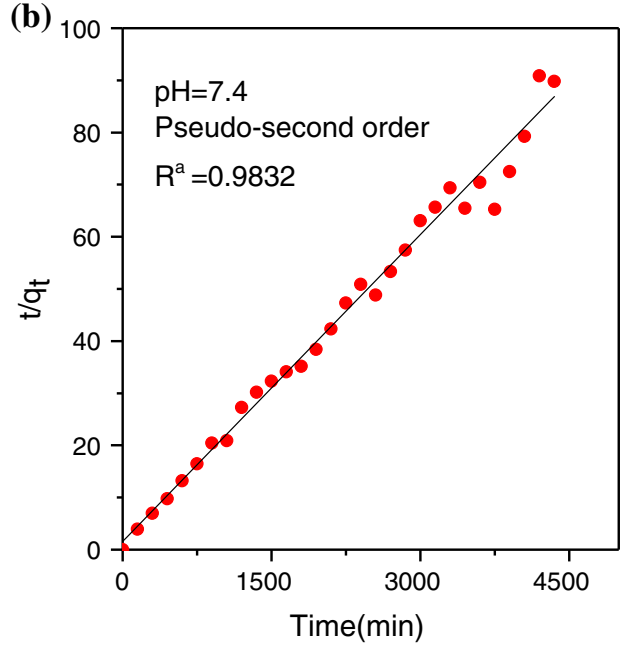

Fig. 7 Data fitting for PE anion release from FPEGPE nanocomposite using pseudo-second-order kinetic model into PBS at pH 4.8 (a) and $\mathrm{pH}$ 7.4 (b)

Table 1 The correlation coefficient $\left(R^{2}\right)$, rate constant $(k)$, and half-time $\left(t_{1 / 2}\right)$ obtained by fitting the PE anion release data from the FPEGPE nanocomposite into phosphate buffered solution at $\mathrm{pH} 4.8$ and 7.4

\begin{tabular}{llllll}
\hline Aqueous solution & $\begin{array}{l}\text { Saturated release } \\
(\%)\end{array}$ & $R^{2}$ & & Rate constant $(k)^{\mathrm{a}}\left(\mathrm{mg} \mathrm{min}^{-1}\right)$ & $t_{1 / 2}^{\mathrm{a}}\left(\mathrm{min}^{2}\right)$ \\
\cline { 2 - 5 } & & $\begin{array}{l}\text { Pseudo-first- } \\
\text { order }\end{array}$ & $\begin{array}{l}\text { Pseudo-second- } \\
\text { order }\end{array}$ & $\begin{array}{l}\text { Parabolic } \\
\text { diffusion }\end{array}$ & \\
\hline pH 4.8 & 60.8 & 0.3673 & 0.9874 & 0.4576 & $4.85 \times 10^{-4}$ \\
pH 7.4 & 83.1 & 0.3294 & 0.9832 & 0.4164 & $2.42 \times 10^{-4}$ \\
\hline
\end{tabular}

${ }^{a}$ Estimated using pseudo-second-order kinetics

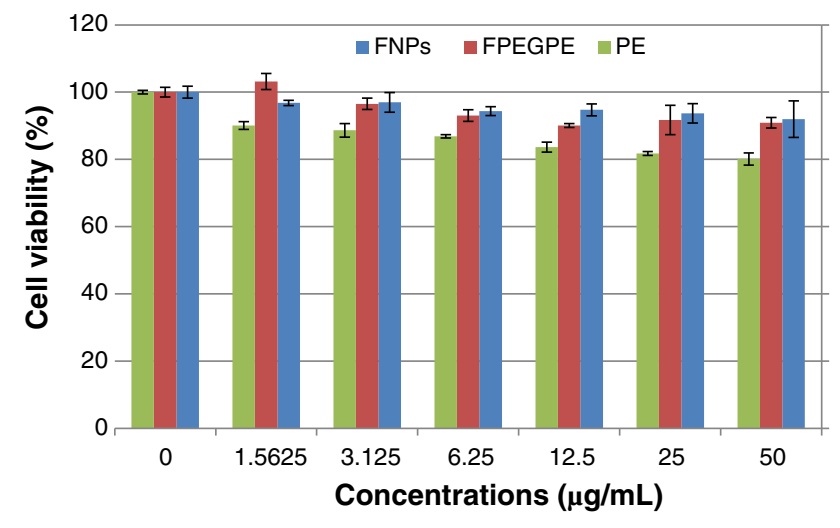

Fig. 8 Cytotoxicity effects of FNPs, PE, and FPEGPE nanocomposite on $3 \mathrm{~T} 3$ cells as determined by MTT assay after $72 \mathrm{~h}$ of exposure

In vitro bioassay

The cell proliferation assay (MTT) is one of the several in vitro methods used to study toxicity potentials of active compounds [56,57]. Figure 8 shows the toxicity effect of pure PE, FNPs, and the synthesized iron oxide coated with
PEG-PE (FPEGPE) on normal fibroblast cell (3T3) at $72 \mathrm{~h}$ post treatment using cell proliferation assay (MTT) between the dose ranges of $0.0-50 \mu \mathrm{g} \mathrm{mL}^{-1}$.

For the three compounds tested, dose-dependent properties were observed in which it decreases the cellular viability after $72 \mathrm{~h}$. Pure PE was found to have higher toxicity effect in a dose-dependent fashion compared to FPEGPE nanocomposite and FNPs. There was $20 \%$ decrease in cell viability at $50 \mu \mathrm{g} \mathrm{mL}^{-1}$ exposure to PE, while FNPs and FPEGPE nanocomposite showed less than $10 \%$ decrease on fibroblast viability. Hence, pure drug PE causes a slightly higher toxicity to $3 \mathrm{~T} 3$ cell in a dosedependent manner than FPEGPE nanocomposite and FNPs.

We had reported earlier similar toxicity pattern, where PE-loaded iron oxide-chitosan (FCPE) nanoparticles tested on fibroblast cell line [40]. The results show that FNPs loaded with PE and coated with either chitosan or PEG showed decrease toxicity potential than pure PE. This may be attributed to the sustained, controlled release potential seen in both materials. The decrease toxicity prospective of this delivery system together with the controlled-release effects should be explored further for better drug delivery application. 


\section{Conclusion}

Due to low toxicity effect of FNPs against mouse normal fibroblast (3T3) cell lines, magnetite FNPs which were synthesized by coprecipitation method were coated with PEG-PE to form the FPEGPE nanocomposite. The XRD patterns show pure phase magnetite FNPs with mean particle size of $9 \pm 2 \mathrm{~nm}$. After coating, the FPEGPE nanocomposite composed of pure magnetite core with slightly bigger mean particle size of $13 \pm 2 \mathrm{~nm}$. The FTIR shows the vibrational modes of the magnetite and the attachment of PEG-PE onto the surface of FNPs. VSM studies confirm the superparamagnetic properties of FNPs and the FPEGPE nanocomposite. Although, it was found that the release profiles of PE from FPEGPE nanocomposite into phosphate buffered solution are of controlled manner with the total release equilibrium of 60.8 and $83.1 \%$ when exposed to $\mathrm{pH}$ 7.4 and 4.8 at 4223 and $1231 \mathrm{~min}$, respectively, but due to the stronger binding of chitosan ( $\mathrm{NH}_{3}$ active group) compared to PEG (O-H active group), the drug ( $\mathrm{PE}$ ) can be released more slowly from the FCPE carriers, when chitosan was used as a coating polymer compared to FPEGPE nanocomposite in which PEG was used as the coating polymer. The cytotoxic effects of FNPs, free PE, and FPEGPE were determined against mouse normal fibroblast (3T3) cell lines and show slight decrease in the viability of 3T3 cells could be directly proportional to the concentrations used. However, pure PE presented slightly higher toxicity than the FNPs and FPEGPE nanocomposite. The decrease toxicity prospective of this new nanocomposite compared to pure drug (PE) together with controlled-release properties offers a great potential of this new nanocomposite to be used for the treatment of hypertension.

Acknowledgements The authors would like to thank the Ministry of Science, Technology and Innovation of Malaysia (MOSTI) under National Nanotechnology Initiative, Grant NND/NA/(1)/TD11-010 (Vot No. 5489100) for supporting this research.

Conflict of interest All authors declare no conflict of interests in this work.

Open Access This article is distributed under the terms of the Creative Commons Attribution License which permits any use, distribution, and reproduction in any medium, provided the original author(s) and the source are credited.

\section{References}

1. Damgé C, Socha M, Ubrich N, Maincent P (2009) Poly( $\varepsilon$-caprolactone)/eudragit nanoparticles for oral delivery of aspartinsulin in the treatment of diabetes. J Pharm Sci 99:879-889

2. Damgé C, Maincent P, Ubrich N (2007) Oral delivery of insulin associated to polymeric nanoparticles in diabetic rats. J Control Release 117:163-170
3. Oyarzun-Ampuero FA, Brea J, Loza MI, Torres D, Alonso MJ (2009) Chitosan-hyaluronic acid nanoparticles loaded with heparin for the treatment of asthma. Int J Pharm 381:122-129

4. Kumar M, Kong X, Behera AK, Hellermann GR, Lockey RF, Mohapatra SS (2003) Chitosan IFN- $\gamma$-pDNA nanoparticle (CIN) therapy for allergic asthma. Genet Vaccines Ther 1:3

5. Wang W, Zhu R, Xie Q, Li A, Xiao Y, Li K, Liu H, Cui D, Chen Y, Wang S (2012) Enhanced bioavailability and efficiency of curcumin for the treatment of asthma by its formulation in solid lipid nanoparticles. Int J Nanomed 7:3667-3677

6. Kim M-H, Seo J-H, Kim H-M, Jeong H-J (2014) Zinc oxide nanoparticles, a novel candidate for the treatment of allergic inflammatory diseases. Eur J Pharmacol 738:31-39

7. Liu L, Xu K, Wang H, Tan PKJ, Fan W, Venkatraman SS, Li L, Yang Y-Y (2009) Self-assembled cationic peptide nanoparticles as an efficient antimicrobial agent. Nat Nanotech 4:457-463

8. Rai M, Yadav A, Gade A (2009) Silver nanoparticles as a new generation of antimicrobials. Biotechnol Adv 27:76-83

9. Anderson LJ, Holden S, Davis B, Prescott E, Charrier CC, Bunce NH, Firmin DN, Wonke B, Porter J, Walker JM (2001) Cardiovascular T2-star (T2*) magnetic resonance for the early diagnosis of myocardial iron overload. Eur Heart J 22:2171-2179

10. Jendelová $P$, Herynek V, Urdzikova L, Glogarová KI, Kroupová J, Andersson B, Bryja VTZ, Burian M, Hájek M, Syková E (2004) Magnetic resonance tracking of transplanted bone marrow and embryonic stem cells labeled by iron oxide nanoparticles in rat brain and spinal cord. J Neurosci Res 76:232-243

11. Leuschner C, Kumar CSSR, Hansel W, Soboyejo W, Zhou J, Hormes J (2006) LHRH-conjugated magnetic iron oxide nanoparticles for detection of breast cancer metastases. Breast Cancer Res Treat 99:163-176

12. Wang S, Chen KJ, Wu TH, Wang H, Lin WY, Ohashi M, Chiou PY, Tseng HR (2010) Photothermal effects of supramolecularly assembled gold nanoparticles for the targeted treatment of cancer cells. Angew Chem Int Ed 49:3777-3781

13. Yin Win K, Feng S-S (2005) Effects of particle size and surface coating on cellular uptake of polymeric nanoparticles for oral delivery of anticancer drugs. Biomaterials 26:2713-2722

14. He C, Hu Y, Yin L, Tang C, Yin C (2010) Effects of particle size and surface charge on cellular uptake and biodistribution of polymeric nanoparticles. Biomaterials 31:3657-3666

15. Jordan A, Scholz R, Maier-Hauff K, van Landeghem FKH, Waldoefner N, Teichgraeber U, Pinkernelle J, Bruhn H, Neumann F, Thiesen B (2006) The effect of thermotherapy using magnetic nanoparticles on rat malignant glioma. J Neuro-Oncol 78:7-14

16. Dessy A, Piras AM, Schirò G, Levantino M, Cupane A, Chiellini F (2011) Hemoglobin loaded polymeric nanoparticles: preparation and characterizations. Eur J Pharm Sci 43:57-64

17. Davis FF (2002) The origin of pegnology. Adv Drug Deliver Rev $54: 457-458$

18. Malam Y, Loizidou M, Seifalian AM (2009) Liposomes and nanoparticles: nanosized vehicles for drug delivery in cancer. Trends Pharmacol Sci 30:592-599

19. Hussein-Al-Ali SH, El Zowalaty ME, Hussein MZ, Ismail M, Dorniani D, Webster TJ (2014) Novel kojic acid-polymer-based magnetic nanocomposites for medical applications. Int J Nanomed 9:351-362

20. Unsoy G, Yalcin S, Khodadust R, Mutlu P, Gunduz U (2012) In situ synthesis and characterization of chitosan coated iron oxide nanoparticles and loading of doxorubicin. In: Nanocon. Brno, Czech Republic

21. Kaaki K, Hervé-Aubert K, Chiper M, Shkilnyy A, Soucé M, Benoit R, Paillard A, Dubois P, Saboungi M-L, Chourpa I (2011) Magnetic nanocarriers of doxorubicin coated with poly(ethylene glycol) and folic acid: relation between coating structure, surface 
properties, colloidal stability, and cancer cell targeting. Langmuir 28:1496-1505

22. Saboktakin MR, Tabatabaie R, Maharramov A, Ramazanov MA (2010) Synthesis and characterization of superparamagnetic chitosan-dextran sulfate hydrogels as nano carriers for colonspecific drug delivery. Carbohydr Polym 81:372-376

23. Dorniani D, Bin Hussein MZ, Kura AU, Fakurazi S, Shaari AH, Ahmad Z (2013) Preparation and characterization of 6-mercaptopurine-coated magnetite nanoparticles as a drug delivery system. Drug Des Devel Ther 7:1015-1026

24. Qu J-B, Shao H-H, Jing G-L, Huang F (2013) PEG-chitosancoated iron oxide nanoparticles with high saturated magnetization as carriers of 10-hydroxycamptothecin: preparation, characterization and cytotoxicity studies. Colloids Surf B 102:37-44

25. Dorniani D, Hussein MZ, Kura AU, Fakurazi S, Shaari AH, Ahmad $\mathrm{Z}$ (2011) Preparation of $\mathrm{Fe}_{3} \mathrm{O}_{4}$ magnetic nanoparticles coated with gallic acid for drug delivery. Int J Nanomed 7:5745-5756

26. Dorniani D, Kura AU, Hussein-Al-Ali SH, Hussein MZB, Fakurazi S, Shaari AH, Ahmad Z (2014) In vitro sustained release study of gallic acid coated with magnetite-PEG and magnetitePVA for drug delivery system. Sci World J. doi: 10.1155/2014/ 416354

27. Sun C, Sze R, Zhang M (2006) Folic acid-PEG conjugated superparamagnetic nanoparticles for targeted cellular uptake and detection by MRI. J Biomed Mater Res A 78:550-557

28. Hussein-Al-Ali SH, Arulselvan P, Fakurazi S, Hussein MZ, Dorniani D (2014) Arginine-chitosan- and arginine-polyethylene glycol-conjugated superparamagnetic nanoparticles: preparation, cytotoxicity and controlled-release. J Biomater Appl. doi: 10.1177/0885328213519691

29. Hussein-Al-Ali SH, Arulselvan P, Hussein MZ, Fakurazi S, Ismail M, Dorniani D, El Zowalaty ME (2014) Synthesis, characterization, controlled release and cytotoxic effect studies of anthranilic acid loaded chitosan and polyethylene glycol-magnetic nanoparticles on murine macrophage RAW 264.7 cells. Nano. doi: 10.1142/S1793292014500167

30. Thom T, Haase N, Rosamond W, Howard VJ, Rumsfeld J, Manolio T, Zheng Z-J, Flegal K, O'donnell C, Kittner S (2006) Heart disease and stroke statistics-2006 update: a report from the American Heart Association Statistics Committee and Stroke Statistics Subcommittee. Circulation 113:e85-e151

31. Denkbaş EB, Kiliçay E, Birlikseven C, Öztürk E (2002) Magnetic chitosan microspheres: preparation and characterization. React Funct Polym 50:225-232

32. Li G-Y, Y-r Jiang, K-1 Huang, Ding P, Chen J (2008) Preparation and properties of magnetic $\mathrm{Fe}_{3} \mathrm{O}_{4}$-chitosan nanoparticles. J Alloys Compd 466:451-456

33. Remková A, Kratochvil'ová H, Durina J (2008) Impact of the therapy by renin-angiotensin system targeting antihypertensive agents perindopril versus telmisartan on prothrombotic state in essential hypertension. J Hum Hypertens 22:338-345

34. Zannad F, Bernaud CM, Fay R (1999) Double-blind, randomized, multicentre comparison of the effects of amlodipine and perindopril on $24 \mathrm{~h}$ therapeutic coverage and beyond in patients with mild to moderate hypertension. J Hypertens 17:137-146

35. Lee H, Shao H, Huang Y, Kwak B (2005) Synthesis of MRI contrast agent by coating superparamagnetic iron oxide with chitosan. IEEE Trans Magn 41:4102-4104

36. Kura AU, Hussein-Al-Ali SH, Hussein MZ, Fakurazi S, Arulselvan P (2012) Development of a controlled-release antiparkinsonian nanodelivery system using levodopa as the active agent. Int J Nanomed 8:1103-1110

37. Wang C, Feng L, Yang H, Xin G, Li W, Zheng J, Tian W, Li X (2012) Graphene oxide stabilized polyethylene glycol for heat storage. Phys Chem Chem Phys 14:13233-13238
38. Chen T-J, Cheng T-H, Chen C-Y, Hsu SCN, Cheng T-L, Liu G-C, Wang Y-M (2009) Targeted Herceptin-dextran iron oxide nanoparticles for noninvasive imaging of HER2/neu receptors using MRI. J Biol Inorg Chem 14:253-260

39. Sangeetha J, Philip J (2012) The interaction, stability and response to an external stimulus of iron oxide nanoparticle-casein nanocomplexes. Colloids Surf A 406:52-60

40. Dorniani D, Hussein MZB, Kura AU, Fakurazi S, Shaari AH, Ahmad Z (2013) Sustained release of prindopril erbumine from its chitosan-coated magnetic nanoparticles for biomedical applications. Int J Mol Sci 14:23639-23653

41. Calmon MF, de Souza AT, Candido NM, Raposo MIB, Taboga S, Rahal P, Nery JG (2012) A systematic study of transfection efficiency and cytotoxicity in HeLa cells using iron oxide nanoparticles prepared with organic and inorganic bases. Colloids Surf B 100:177-184

42. Dodi G, Hritcu D, Lisa G, Popa MI (2012) Core-shell magnetic chitosan particles functionalized by grafting: synthesis and characterization. Chem Eng J 203:130-141

43. Mürbe J, Rechtenbach A, Töpfer JR (2008) Synthesis and physical characterization of magnetite nanoparticles for biomedical applications. Mater Chem Phys 110:426-433

44. Shameli K, Bin Ahmad M, Jazayeri SD, Sedaghat S, Shabanzadeh P, Jahangirian H, Mahdavi M, Abdollahi Y (2012) Synthesis and characterization of polyethylene glycol mediated silver nanoparticles by the green method. Int J Mol Sci 13:6639-6650

45. Kipkemboi PK, Kiprono PC, Sanga JJ (2003) Vibrational spectra of t-butyl alcohol, t-butylamine and t-butyl alcohol + t-butylamine binary liquid mixtures. Bull Chem Soc Ethiopia $17: 211-218$

46. Smith BC (1999) Infrared spectral interpretation: a systematic approach. CRC Press, Boca Raton, FL

47. Macêdo RO, Gomes do Nascimento $T$, Soares Aragăo $C F$, Barreto Gomes AP (2000) Application of thermal analysis in the characterization of anti-hypertensive drugs. J Therm Anal Calorim 59:657-661

48. Kayal S, Ramanujan RV (2010) Doxorubicin loaded PVA coated iron oxide nanoparticles for targeted drug delivery. Mater Sci Eng C 30:484-490

49. Debrassi A, Corrêa AF, Baccarin T, Nedelko N, Ślawska-Waniewska A, Sobczak K, Dłużewski P, Greneche J-M, Rodrigues CvA (2012) Removal of cationic dyes from aqueous solutions using $\mathrm{N}$-benzyl- $\mathrm{O}$-carboxymethylchitosan magnetic nanoparticles. Chem Eng J 183:284-293

50. Kumar R, Inbaraj BS, Chen BH (2010) Surface modification of superparamagnetic iron nanoparticles with calcium salt of poly(Y-glutamic acid) as coating material. Mater Res Bull 45:1603-1607

51. Qu J, Liu G, Wang Y, Hong R (2010) Preparation of $\mathrm{Fe}_{3} \mathrm{O}_{4-}$ chitosan nanoparticles used for hyperthermia. Adv Powder Technol 21:461-467

52. L-y Zhang, X-j Zhu, H-w Sun, Chi G-r Xu, J-x Sun Y-l (2010) Control synthesis of magnetic $\mathrm{Fe}_{3} \mathrm{O}_{4}$-chitosan nanoparticles under UV irradiation in aqueous system. Curr Appl Phys $10: 828-833$

53. Hussein-Al-Ali SH, Al-Qubaisi M, Hussein MZ, Ismail M, Zainal Z, Hakim MN (2012) In vitro inhibition of histamine release behavior of cetirizine intercalated into $\mathrm{Zn} / \mathrm{Al}$-and $\mathrm{Mg} / \mathrm{Al}$-layered double hydroxides. Int J Mol Sci 13:5899-5916

54. Dong L, Yan L, Hou W-G, Liu S-J (2010) Synthesis and release behavior of composites of camptothecin and layered double hydroxide. J Solid State Chem 183:1811-1816

55. Ho Y-S, Ofomaja AE (2006) Pseudo-second-order model for lead ion sorption from aqueous solutions onto palm kernel fiber. J Hazard Mater 129:137-142 
56. Valiathan C, McFaline JL, Samson LD (2012) A rapid survival assay to measure drug-induced cytotoxicity and cell cycle effects. DNA Repair 11:92-98
57. Niles AL, Moravec RA, Riss TL (2008) Update on in vitro cytotoxicity assays for drug development. Expert Opin Drug Discov 3:655-669 